\title{
Presentación de un caso de Afibrinogenemia
}

\author{
Doctor Roberto Durán Forero
}

Nombre: C. O. Edad: treinta y dos años. Carnet No 79725.

Embarazo número 4. Tres partos a término, tres hijos vivos. Esta enferma de pequeña talla tiene una estrechez pélvica absoluta por lo cual le practicaron una cesárea en el Hospital de San Juan de Dios y dos en la Clínica Primero de Mayo. Ingresa a esta última el día 16 de febrero de 1956 a las 22. Enferma en el noveno mes de embarazo con altura uterina de $30 \mathrm{cs}$. T. A.: 15,5 por 9,5. Auscultación positiva, movimientos positivos. Dice haber sentido dolores desde las 17:00 de ayer; ahora cada 5 minutos. Desde las 19:00 comenzó a sangrar continuamente y aumentó tonus y dolor. Al TV vulva, vagina y periné normales. Cuello incompletamente borrado con $3 \mathrm{cs}$. de dilatación, hemorragia abundante. Se hace el diagnóstico de Placenta Previa y se pasa a cirugía.

Pre-medicación: una ampolleta de atropina (un cuarto de miligramo): T. A. 130 por 80 . Preparación de rutina. Dextrosa al $5 \%$ vía venosa.

22.20: anestesia local: 2 c. c. de procaína al $2 \%$ a nivel de 3 a y 4 a lumbar y punción raquídea entre $3^{\mathrm{a}}$ y $4^{\mathrm{a}}$.

Estado general de la paciente bueno. Inyección subdural de escurocaína 3 c. c. 150 mgrs. en decúbito lateral derecho con elevador cervical.

A las 22.35 se inicia la intervención con resección cicatriz media-infra_umbilical. Cesárea por la técnica clásica trans-peritoneal. Al abrir el segmento se cae sobre la placenta que se rompe y se extrae a las 22.53 un feto sexo masculino de 2.125 gramos de peso y 46 cs. de talla. El feto respira mal y es necesario pasarlo al resucitador. En la cara anterior del segmento se veía un hemazoma de unos $5 \mathrm{cs}$. de diámetro.

A las 22.55: pitocin intra-mural. T. A.: 0 por 0 Efedrina intravenosa: $20 \mathrm{mgrs}$ y $20 \mathrm{mgrs}$ intra-muscular. Se inicia transfusión de sangre total: $1.000 \mathrm{c}$. c. 
La T. A. entre las 23.05 y las 23.30 fluctúa entre 4 por 2 y 5 por 3. A esta hora se nota que la paciente sangra discretamente por la vagina y que la sangre no forma coágulo. Se le inyecta un frasco de sulfato de protamina vía venosa.

23.50 revisión del útero.

A las 24 se practica taponamiento con oxicel y compresas, ergotrate en el cuello. Continúa sangrando abundantemente.

A la 1.17 del 17 nuevo taponamiento.

A la 1.5 sangra por la sutura, por las punturas de las inyecciones y por la mucosa de los grandes labios y de las encías.

3.30: la enferma no se recupera del schok; se le pasa largactil gota a gota y fenergán. Se le da ciclo eter-oxígeno y se rein. terviene nuevarnente practicando histerectomía sub-total. Se encuentra abundante cantidad de sangre en la cavidad peritoneal.

4 a. m. muere la enferma.

Desde las 23.40 en adelante hasta la muerte de esta paciente se le aplican 9.250 c. c. de sangre total; 9.750 c. c. de plasma; 400 mgrs. de ACTH; sulfato de protamina; ergotrate intra-muscular e intra-venoso; pitocín; vitamina $\mathrm{K}$; levofed.

Desde que la paciente entró en schok en ningún momento su sangre formó coágulo alguno. Los tubos de ensayo que' se llenaron con el fín de mandarlos analizar en ningún momento se observó tendencia a la coagulación. 